Article

\title{
Performance Enhanced SAPO-34 Catalyst for Methanol to Olefins: Template Synthesis Using a $\mathrm{CO}_{2}$-Based Polyurea
}

\author{
Yuehong Yu ${ }^{1}$, Jiaxiang Qin ${ }^{1}$, Min Xiao ${ }^{1, *}$, Shuanjin Wang ${ }^{1 \oplus}$, Dongmei Han ${ }^{2}$ and \\ Yuezhong Meng ${ }^{1,2, *}$ \\ 1 The Key Laboratory of Low-Carbon Chemistry \& Energy Conservation of Guangdong Province/State Key \\ Laboratory of Optoelectronic Materials and Technologies, Sun Yat-Sen University, Guangzhou 510275, \\ China; yuyueh@mail2.sysu.edu.cn (Y.Y.); qinjx3@mail2.sysu.edu.cn (J.Q.); wangshj@mail.sysu.edu.cn (S.W.) \\ 2 School of Chemical Engineering and Technology, Sun Yat-Sen University, Guangzhou 510275, China; \\ handongm@mail.sysu.edu.cn \\ * Correspondence: stsxm@mail.sysu.edu.cn (M.X.); mengyzh@mail.sysu.edu.cn (Y.M.); \\ Tel./Fax: +86-20-8411-4113 (Y.M.)
}

Received: 20 November 2018; Accepted: 17 December 2018; Published: 28 December 2018

check for updates

\begin{abstract}
Introducing mesopores into the channels and cages of conventional micropores CHA (Chabazite) topological structure SAPO-34 molecular sieves can effectively improve mass transport, retard coke deposition rate and enhance the catalytic performance for methanol to olefins (MTO) reaction, especially lifetime and olefins selectivity. In order to overcome the intrinsic diffusion limitation, a novel $\mathrm{CO}_{2}$-based polyurea copolymer with affluent amine group, ether segment and carbonyl group has been firstly applied to the synthesis of SAPO-34 zeolite under hydrothermal conditions. The as-synthesized micro-mesoporosity SAPO-34 molecular sieve catalysts show heterogeneous size distribution mesopores and exhibit slightly decrease of BET surface area due to the formation of defects and voids. Meanwhile, the catalysts exhibit superior catalytic performance in the MTO reaction with more than twice prolonged catalytic lifespan and improvement of selectivity for light olefins compared with conventional microporous SAPO-34. The methodology provides a new way to synthesize and control the structure of SAPO-34 catalysts.
\end{abstract}

Keywords: molecular sieves; SAPO-34; $\mathrm{MTO}$; $\mathrm{CO}_{2}$-based polyuria; mesoporogen

\section{Introduction}

Methanol to lower olefins reaction is a critical process for conversion of nonoil resources to chemicals through methanol, and light olefins especially ethylene and propylene have been widely applied in polymerization reaction and petrochemical industry [1-6]. Several types of molecular sieves for the MTO reaction have been intensively studied, and the most typically are SAPO-34 $[7,8]$, ZSM-5 [9-11], and SSZ-13 [12-14]. Among these catalysts, SAPO-34 has drawn the most attention due to its special framework with a CHA cage (9.4 $\AA$ ) and 8-ring pore openings ( $0.38 \AA 0.38 \AA$ ) [15], as well as mild acidity [16-18] which result in excellent catalytic performance [3,19-21]. However, the CHA topological structure has both advantages and disadvantages, the narrow 8-ring pore openings gives rise to a high lower olefins selectivity due to the shape selectivity of zeolites, while it limits the mass transport of big size by-products. Moreover, the produced large coke species can block the channels and interdict the contact of raw material with active sites, leading to a rapid decline of both methanol conversion and olefins selectivity [4,22-24]. In this respect, overcoming the mass transfer restriction and retarding the coke deposition rate are vital to the extension of the catalytic lifespan. 
Several theoretical models have been established to elaborate coke formation and distribution, models that quantitatively and theoretically determine coke formation and distribution are random-walk model [25], percolation model [26-29], Monte-Carlo model [30] and other different models [31-33]. Ton V. W. Janssens [34] proposed a simple model contains the first-order rate constant to measure catalyst activity and a deactivation coefficient to characterize the deactivation behavior. Wei et al. [35] established a discrete Ising model for the deactivation of SAPO-34 zeolite inspired from the traditional game Go and predicted an acid percentage of $57 \%$ to make full use of each acid cage and an optimal acid percent of $66 \%$ to obtain maximum access to the active sites. The existence of mesopores/macropores introduces defects and voids into the crystals which can effectively increase the accessibility of the catalytic active sites and the utilization of the catalyst, i.e., retards the coke deposition rate and improve the lifetime performance [36].

So far, many effective methods [37] have been used to introduce meso/macropores into the SAPO-34 molecular sieves, such as post-treatment method (etching by acid to remove $\mathrm{Al}$ atoms [38] and alkali to remove $\mathrm{Si}$ atoms [39]), confined space synthesis method [40,41], hard template method [42] and soft template method $[8,43]$. Soft templates that can give rise to mesostructure mainly include poly-quaternary ammonium organic surfactant, amphiphilic organosilane surfactant [3], cationic water soluble polymers such as polydiallyl-dimethylammonium chloride (PDADMAC) and PDDAM [44,45], nonionic water soluble polymers such as P123 [46], PEI [47]. Among these methods, the polymers have been paid much attention due to their good thermal stability and strong interaction of the templates with silica species, adjustable composition and low cost [48]. Yu et al. [8] synthesized a tri-level hierarchical SAPO-34 zeolite with micro-meso-macroporosity by introducing PEO (Polyoxyethylene) into the starting gel and successfully prolonged the lifetime performance.

Herein, we report a strategy through introducing a novel $\mathrm{CO}_{2}$-based polyurea into the starting gel of synthesizing SAPO-34 molecular sieves, which acting as mesoporogen. The $\mathrm{CO}_{2}$-based polyurea was synthesized by a facile one step reaction of $\mathrm{CO}_{2}$ with diamine [49]. It contains affluent amine group, ether segment and carbonyl group that have strong affinity with raw materials in the starting gel of synthesizing SAPO-34 molecular sieves, thus makes it easier to be introduced into the channels and cages of the CHA framework to form defects and voids, i.e., mesopores/macropores in the zeolite. The as-synthesized micro-mesoporosity SAPO-34 molecular sieve catalysts show heterogeneous size distribution mesopores and exhibit slightly decrease of BET surface area due to the formation of defects and voids. Meanwhile, the catalysts manifest superior catalytic performance in the MTO reaction with more than twice prolonged catalytic lifespan and improvement of selectivity for light olefins compared with the conventional microporous SAPO-34.

\section{Results and Discussion}

\subsection{Characterizations of Polyurea: ${ }^{1} H-N M R$ and MALDI-TOF-MS}

The structure and molecular weight of the as-synthesized copolymer were confirmed by ${ }^{1} \mathrm{H}-\mathrm{NMR}$ and MALDI-TOF-MS (Matrix-Assisted Laser Desorption/Ionization Time of Flight Mass Spectrometry), and the results are shown in Figures 1 and 2. The disappearance of the proton resonance peak at $2.6 \mathrm{ppm}$ for $\alpha-\mathrm{C}$ and the formation of peak at $3.0 \mathrm{ppm}$ are due to the reaction of amidogen with $\mathrm{CO}_{2}$ to produce urea, which proves the successful synthesis of copolymer polyurea. The gap between each main peak in the MALDI-TOF-MS spectra is 246 in Figure 2, which is consisting with the molecular weight of the unit for the dehydration product of $\mathrm{CO}_{2}$ and diamine, this provides a convincing proof for the successful synthesis of polyurea. And the number average molecular weight (Mn) is 1400 . 


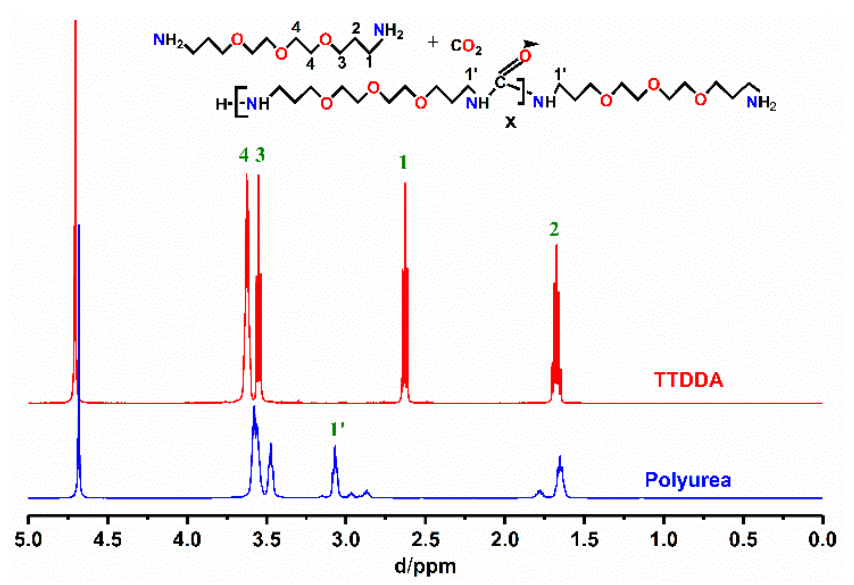

Figure 1. ${ }^{1} \mathrm{H}-\mathrm{NMR}$ spectrum of polyurea and TTDDA.

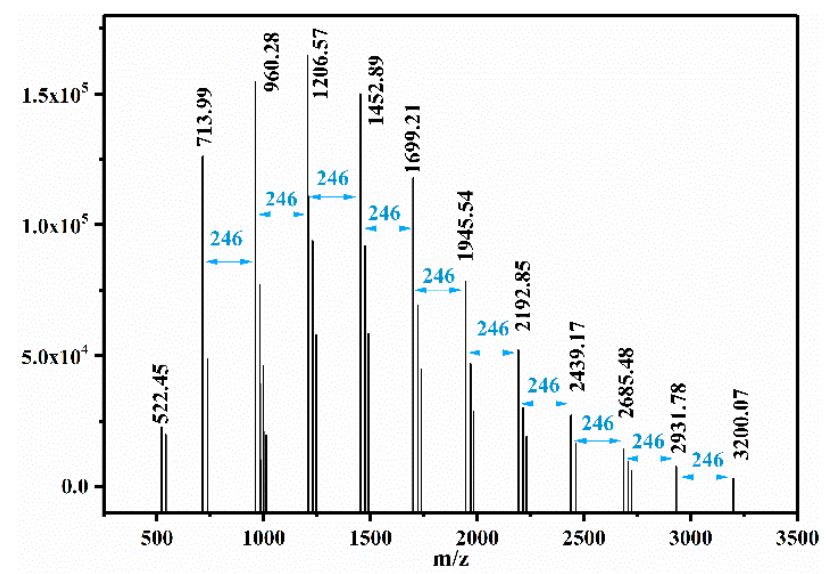

Figure 2. MALDI-TOF-MS spectrum of polyurea.

\subsection{Characterization of the Catalyst}

\subsubsection{Thermogravimetric Analysis and Powder X-ray Diffraction}

The microporous and hierarchically porous SAPO-34 catalysts $\left(\mathrm{PUa}_{0}, \mathrm{PUa}_{0.08}\right.$ and $\left.\mathrm{PUa}_{0.10}\right)$ were synthesized via a conventional hydrothermal method using PUa and triethylamine (TEA) as the mesopore and micropore templates with a gel composition of $1.0 \mathrm{Al}_{2} \mathrm{O}_{3}: 1.0 \mathrm{P}_{2} \mathrm{O}_{5}: 4.0$ TEA: $0.4 \mathrm{SiO}_{2}$ : $100 \mathrm{H}_{2} \mathrm{O}$ : $x$ PUa (Mole ratio, $\mathrm{x}=0,0.08$ and 0.10 ).

TG analyses were carried out to confirm the appropriate temperature for the removal of micropore and mesopore templates, and the results are shown in Figure 3. The weight loss before $200{ }^{\circ} \mathrm{C}$ can be regarded as desorption of the physically adsorbed water, while the weight loss between $200^{\circ} \mathrm{C}$ and $450^{\circ} \mathrm{C}$ belongs to the organic templates in the molecular sieve samples, and the third step of weight loss at temperatures higher than $450{ }^{\circ} \mathrm{C}$ can be described as the removal of organic species embedded in the channels and cages of the SAPO-34 zeolite [50-52]. Sample PUa $\mathrm{P}_{0.08}$ and $\mathrm{PUa}_{0.10}$ show a little higher weight loss before $200{ }^{\circ} \mathrm{C}$ than sample $\mathrm{PUa}_{0}$, which is believed to be due to the higher external surface area of sample PUa $\mathrm{PU}_{0.08}$ and $\mathrm{PUa}_{0.10}$. The weight loss between $200{ }^{\circ} \mathrm{C}$ and $700{ }^{\circ} \mathrm{C}$ are $11.4 \%$, $14 \%, 16.1 \%$ for sample $\mathrm{PUa}_{0}, \mathrm{PUa}_{0.08}$ and $\mathrm{PUa}_{0.10}$, respectively. The extra weight loss of sample $\mathrm{PUa}_{0.08}$ and $\mathrm{PUa}_{0.10}$ belongs to the removal of polyurea in the crystals, which proves that the mesoporogen polyurea inserted into the precursor of SAPO-34 crystals successfully. According to the TG results, the samples were calcined at $600{ }^{\circ} \mathrm{C}$ for $400 \mathrm{~min}$ to remove the templates and the resultant SAPO-34 shows no weight loss up to $900{ }^{\circ} \mathrm{C}$, indicating the complete removal of the templates. 


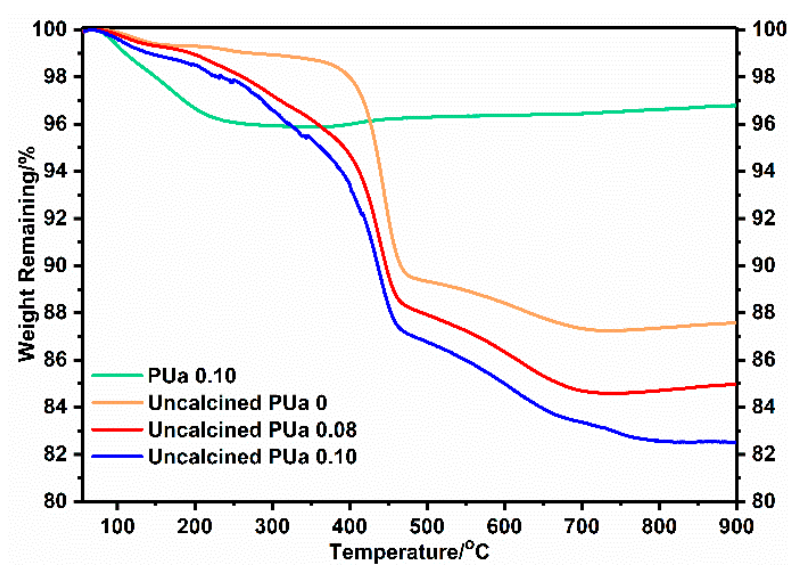

Figure 3. TG profiles of the as-synthesized SAPO-34 samples with and without PUa as mesoporogen.

The XRD patterns of sample $\mathrm{PUa}_{0}, \mathrm{PUa}_{0.08}$ and $\mathrm{PUa}_{0.10}$ shown in Figure 4 reveal the typical diffraction peaks of the CHA zeolite structure. They exhibit high crystallinity without shoulder peak at ca. 20.7, which indicates the phase purity of the SAPO-34 samples synthesized either with or without PUa as mesoporogen. The crystallinities of the samples were calculated in Jade software by fitting the peak area of crystallinity and amorphous peaks, and the obtained crystallinity for the sample $\mathrm{PUa}_{0}$ is $89.6 \%$ while the crystallinity for sample $\mathrm{PUa}_{0.08}$ and $\mathrm{PUa}_{0.10}$ are $79 \%$ and $78 \%$, respectively. The results demonstrate that the addition of polyurea as mesoporogen can decrease the crystallinity of the SAPO-34 molecular sieves to a certain degree. Further increase the $\mathrm{PUa} / \mathrm{Al}_{2} \mathrm{O}_{3}$ ratio to 0.20 would obtain sample ( $\mathrm{PUa}_{0.20}$ ) with very low crystallinity (lower than $40 \%$ ) and irregular particle shape with many big defect, as shown in the Supplementary Materials (Figures S2 and S3).

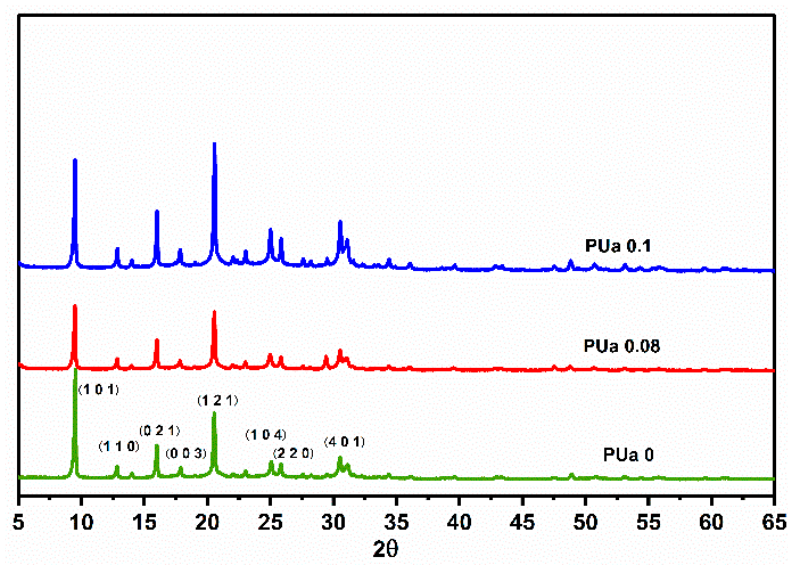

Figure 4. XRD patterns of the as-synthesized SAPO-34 samples with and without PUa as mesoporogen.

\subsubsection{Scanning Electron Microscopy and Transmission Electron Microscopy}

The SEM images shown in Figure 5 present the morphology of the as-synthesized samples with and without polyurea as mesoporogen. The crystal structure of the sample without polyurea appears cubic characteristic with smooth surface, while samples with polyurea as mesoporogen show uneven surface with holes. The average particle size of the crystals increases very slightly with adding polyurea into the gel. Moreover, the amount of larger size crystals decreases, indicating that the particle size becomes more uniform after adding polyurea into the gel system. However, it is apparent that the regularity of the blocks declined due to the introducing of polyurea as mesoporogen. This result is consistent with the crystallinity of the samples calculated according to the XRD patterns. 


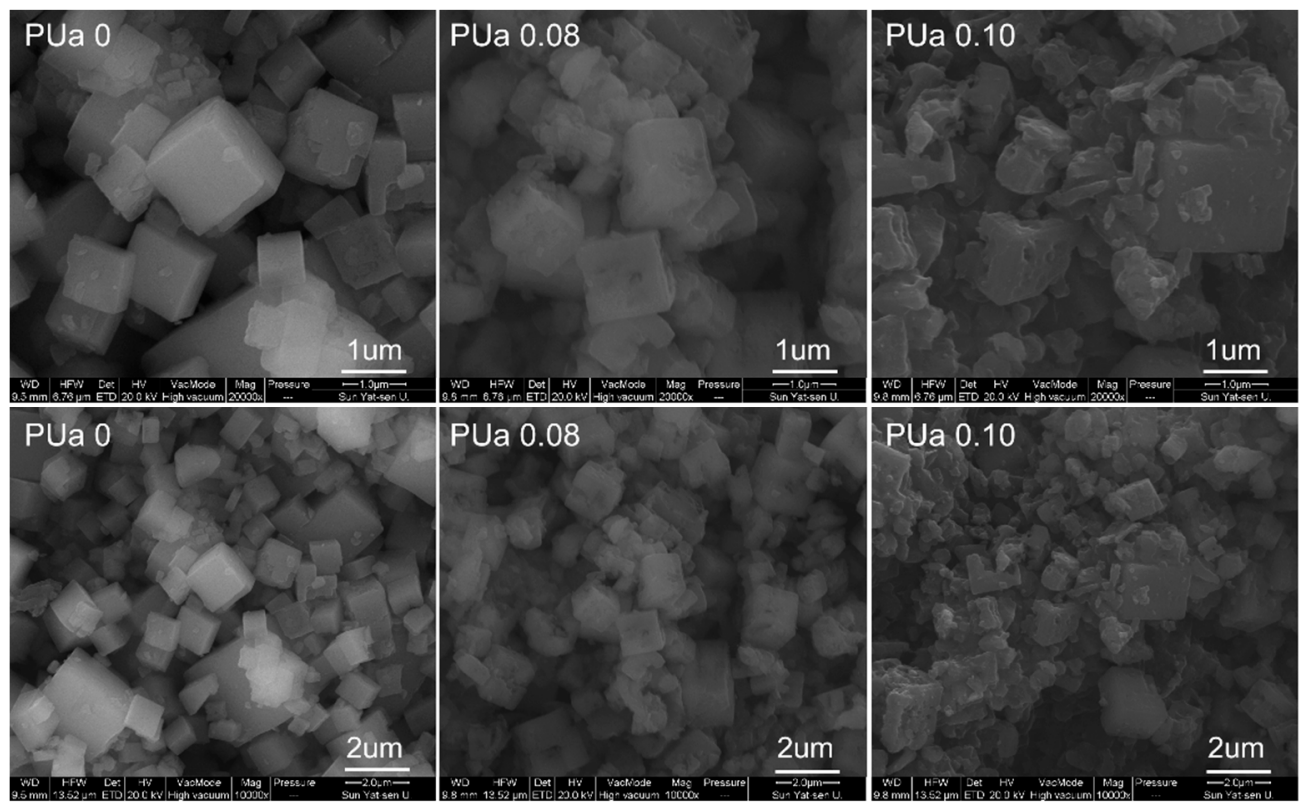

Figure 5. SEM images of the as-synthesized SAPO-34 samples with and without PUa as mesoporogen.

The TEM images in Figure 6 clearly reveal that the sample $\mathrm{PUa}_{0}$ shows solid block morphology with well-defined structure, while sample $\mathrm{PUa}_{0.08}$ and $\mathrm{PUa}_{0.10}$ have the center-hollowed morphology with mesopores and macropores extending along the entire crystals. And sample c, f, i were ball-milled in water with a speed of $300 \mathrm{rpm}$ for $2 \mathrm{~h}$. These results indicate that the SAPO- 34 crystals synthesized with polyurea as mesoporogen have hierarchically porous structure, implying that polyurea is a successful mesoporogen for synthesizing the SAPO-34 molecular sieves.

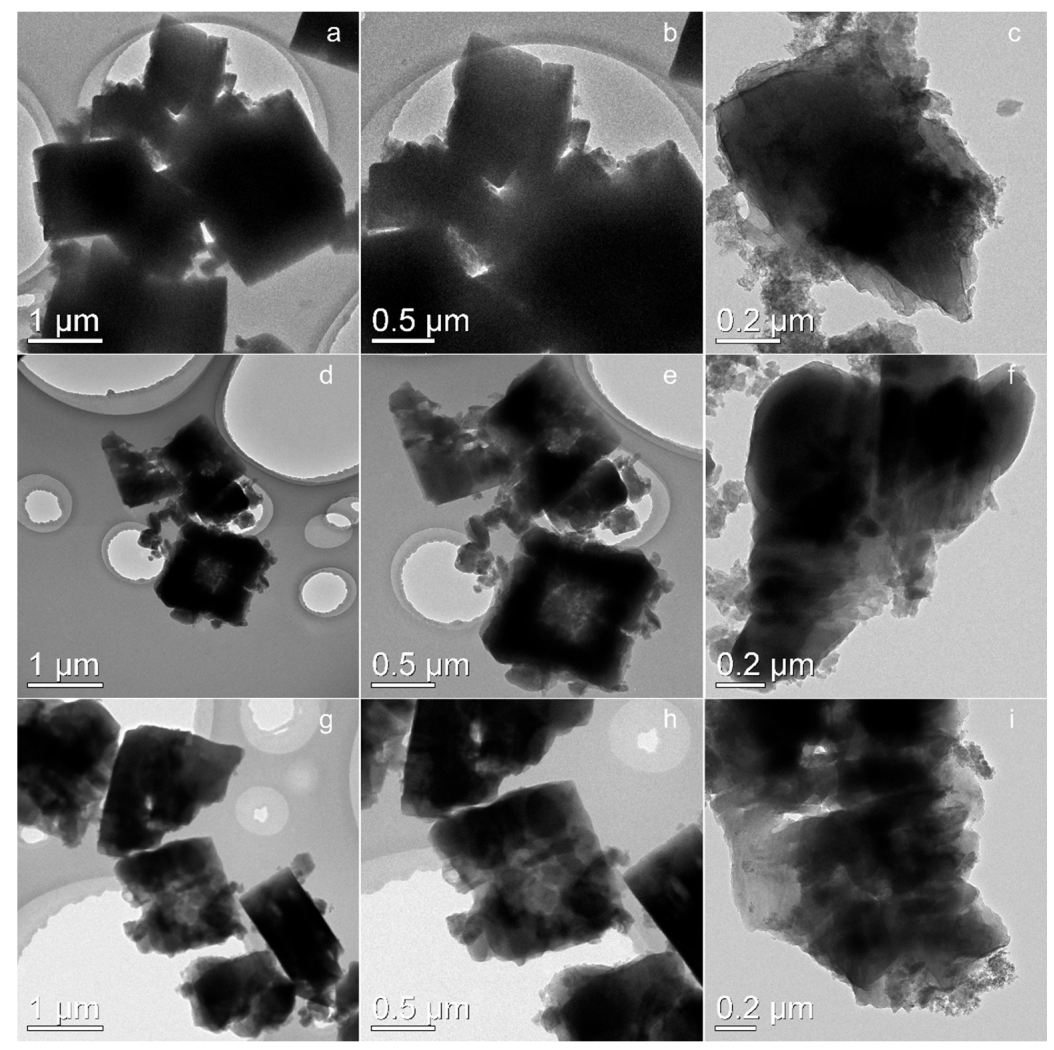

Figure 6. TEM images of the SAPO-34 samples synthesized with and without PUa as mesoporogen, (a-c): $\mathrm{PUa}_{0} ;(\mathbf{d}-\mathbf{f}): \mathrm{PUa}_{0.08} ;(\mathbf{g}-\mathbf{i}): \mathrm{PUa}_{0.10},(\mathbf{c}, \mathbf{f}, \mathbf{i})$ were ball-milled in water. 


\subsubsection{Compositions and Textural Properties}

ICP-OES (Inductively coupled plasma optical emission spectrometry) was applied to determine the chemical compositions of the as-synthesized samples, it can be seen from Table 1 that the introduction of polyurea into the starting gel shows little effect on the element distribution. Compared with the sample $\mathrm{PUa}_{0}, \mathrm{Al}$ contents slightly increase from 0.50 to 0.53 , while $\mathrm{P}$ contents decrease from 0.40 to 0.38 with increasing polyurea content in starting gel for sample $\mathrm{PUa}_{0,08}$ and $\mathrm{PUa}_{0.10}$. This means that the addition of polyurea into the SAPO-34 molecular sieve has no effect on the chemical composition of resulting catalysts.

Table 1. Compositions and textural properties of different SAPO-34 samples.

\begin{tabular}{|c|c|c|c|c|c|c|}
\hline Sample Name & Molar Composition ${ }^{a}$ & $\begin{array}{l}S_{B E T} b \\
\left(m^{2} / g\right)\end{array}$ & $\begin{array}{l}S_{\text {micro }}{ }^{c} \\
\left(\mathrm{~m}^{2} / g\right)\end{array}$ & $\begin{array}{c}S_{\text {ext }}{ }^{c} \\
\left(\mathrm{~m}^{2} / \mathrm{g}\right)\end{array}$ & $\begin{array}{l}V_{\text {micro }}{ }^{c} \\
\left(\mathrm{~cm}^{3} / \mathrm{g}\right)\end{array}$ & $\begin{array}{l}V_{\text {meso }}{ }^{d} \\
\left(\mathrm{~cm}^{3} / g\right)\end{array}$ \\
\hline $\mathrm{PUa}_{0}$ & $\mathrm{Al}_{0.50} \mathrm{P}_{0.40} \mathrm{Si}_{0.09} \mathrm{O}_{2}$ & 641 & 631 & 10 & 0.28 & 0.04 \\
\hline $\mathrm{PUa}_{0.08}$ & $\mathrm{Al}_{0.51} \mathrm{P}_{0.39} \mathrm{Si}_{0.09} \mathrm{O}_{2}$ & 606 & 584 & 22 & 0.27 & 0.22 \\
\hline $\mathrm{PUa}_{0.1}$ & $\mathrm{Al}_{0.53} \mathrm{P}_{0.38} \mathrm{Si}_{0.08} \mathrm{O}_{2}$ & 555 & 506 & 49 & 0.25 & 0.31 \\
\hline
\end{tabular}

${ }^{a}$ Measured by inductively coupled plasma (ICP). ${ }^{\mathrm{b}} \mathrm{S}_{\mathrm{BET}}$ (total surface area) calculated by applying the BET equation using the linear part $(0.05<\mathrm{P} / \mathrm{Po}<0.30)$ of the adsorption isotherm. ${ }^{c} \mathrm{~S}_{\text {micro }}$ (micropore area), $\mathrm{S}_{\text {ext }}$ (external surface area) and $V_{\text {micro }}$ (micropore volume) calculated using the $t$-plot method. ${ }^{d} V_{\text {meso }}$ (mesopore volume) calculated using the BJH method (from desorption).

Nitrogen adsorption-desorption measurement was further applied to characterize the textual properties of the as-synthesized SAPO-34 samples and the results are shown in Table 1 and Figure 7a,b. All samples behave as the type I isotherms which increase rapidly at low relative pressure, proving the existence of micropores in the sample. The curves of sample $\mathrm{PUa}_{0.08}$ and $\mathrm{PUa}_{0.10}$ show a hysteresis loop at high relative pressure region accord with the type-IV isotherms, indicating the presence of mesopores in the samples. The DFT (Density Functional Theory) pore size distribution curves (Figure $7 \mathrm{~b}$ ) clearly indicate that $\mathrm{PUa}_{0.08}$ and $\mathrm{PUa}_{0.10}$ show hierarchically porous structure with the pore size ranging from $1 \mathrm{~nm}$ to $20 \mathrm{~nm}$. The detailed surface area and pore volume data are summarized in Table 1 . The BET surface area decreases with gradually increasing polyurea content. Presumably, this is due to the increase of external surface area, the amount of mesopores and voids in the crystals. Notably, the mesopore volume of the as-synthesized SAPO-34 samples increase apparently from $0.04 \mathrm{~cm}^{3} \cdot \mathrm{g}^{-1}$ to $0.31 \mathrm{~cm}^{3} \cdot \mathrm{g}^{-1}$ with increasing polyurea content in starting gel from 0 to 0.10 , indicating the formation of mesopores in the crystals. This result is consistent with that observed from TEM characterization. The mesopores in the crystals can facilitate the diffusion and mass transportation $[1,37,53]$ of molecules especially coke species in the conversion of methanol to olefins reactions, and then can effectively decrease the coke blocking rate and prolong the full methanol conversion lifespan of the catalysts.

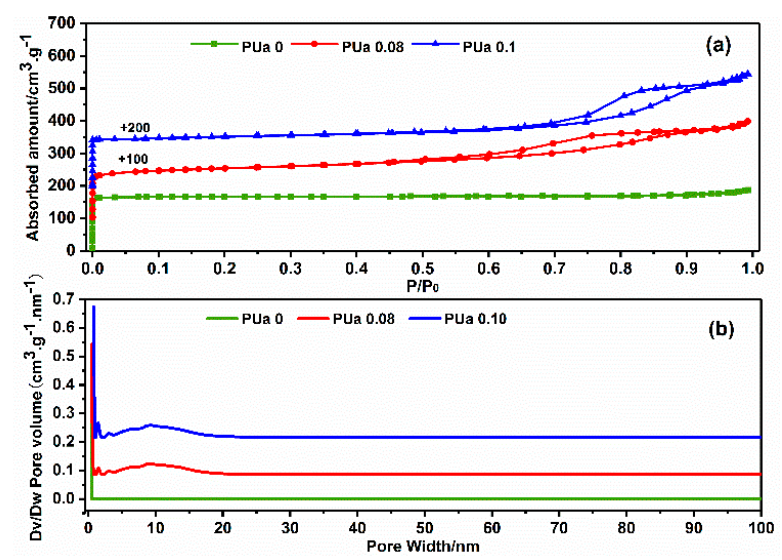

Figure 7. (a) $\mathrm{N}_{2}$ adsorption/desorption isotherms and (b) DFT pore size distribution curves of the as-synthesized SAPO-34 samples with and without PUa as mesoporogen. 


\subsubsection{Chemical Circumstances: Solid State NMR Spectroscopy}

In order to further explore the catalyst structure, solid-state MAS NMR spectroscopy was performed to investigate the chemical environments of the framework atoms in the samples. The results are shown in Figure 8. It can be seen that the ${ }^{27} \mathrm{Al}$ MAS NMR spectra of sample PUa $\mathrm{Pa}_{0}$ presents a strong peak at $40 \mathrm{ppm}$ for the tetrahedral $\mathrm{Al}$ species $\mathrm{Al}(\mathrm{OP})_{4}$, the peak at $-15 \mathrm{ppm}$ represents for the secondary coordination of framework $\mathrm{Al}(4 \mathrm{P})$ sites with strongly adsorbed water [54,55]. However, the tiny peak at $115 \mathrm{ppm}$ represents for spinning sideband appeared at different positions when recorded at various spinning rates [55]. ${ }^{31} \mathrm{P}$ MAS NMR spectra of these samples present a strong peak at $-23 /-25 \mathrm{ppm}$ that belongs to tetrahedral $\mathrm{P}(4 \mathrm{Al})$ framework, while the shoulder peaks at $-12 \mathrm{ppm}$ is assigned to the interaction of partially $\mathrm{P}$ atoms with adsorbed water to form $\mathrm{P}(\mathrm{OAl})_{\mathrm{x}}\left(\mathrm{H}_{2} \mathrm{O}\right)_{\mathrm{y}}$ species [7,55]. The peak intensity of ${ }^{29}$ Si MAS NMR is not obvious in the testing condition.

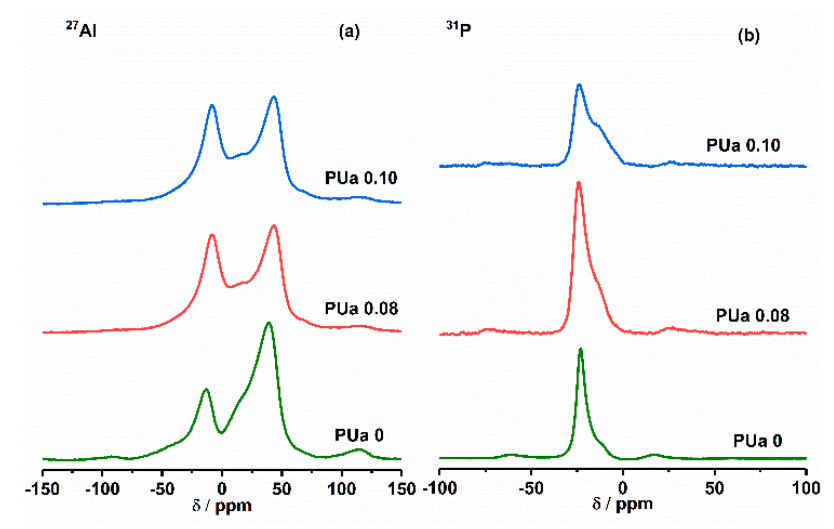

Figure $8 .{ }^{27} \mathrm{Al}(\mathbf{a}),{ }^{31} \mathrm{P}(\mathbf{b})$ MAS NMR spectra of the SAPO-34 samples synthesized with and without PUa as mesoporogen.

\subsubsection{Acidic Properties: $\mathrm{NH}_{3}$-TPD Analysis}

The acidic properties of the samples were examined by $\mathrm{NH}_{3}$-TPD analyses and the results are presented in Figure 9. All curves show a similar tendency and give two desorption peaks at near $160^{\circ} \mathrm{C}$ and $380^{\circ} \mathrm{C}$. The peak at lower temperature for weak acid sites corresponds to the $\mathrm{NH}_{3}$ adsorbed on surface hydroxyl groups ( $\mathrm{Si}-\mathrm{OH}$ and $\mathrm{P}-\mathrm{OH})$, whereas the higher temperature peak for strong acid sites can be assigned as the $\mathrm{NH}_{3}$ desorption from the bridge hydroxyl groups $\mathrm{Si}(\mathrm{OH}) \mathrm{Al}[7,56]$. The relative amount of weak acid sites of sample $\mathrm{PUa}_{0.10}$ slightly increases compared to the sample $\mathrm{PUa}_{0}$ and $\mathrm{PUa}_{0.08}$ due to more mesopores and macropores hence more surface hydroxyl groups. However, the peak area and peak position, i.e., the amount and intensity of strong acid sites decrease with the addition of polyurea as mesoporogen, which is in accordance with the change of silicon content in the samples.

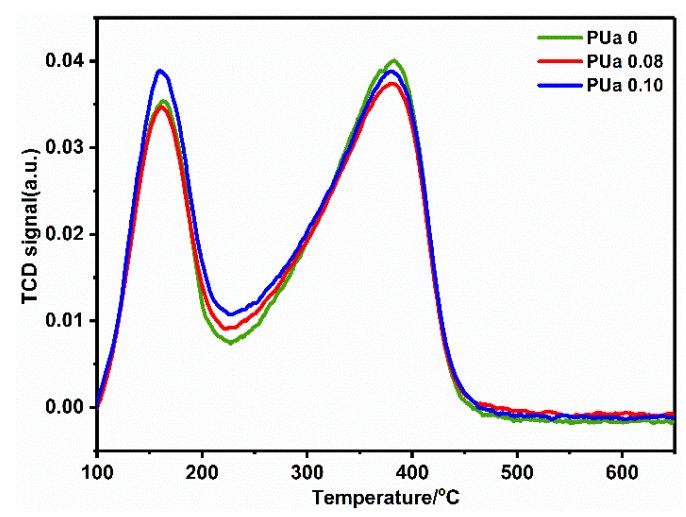

Figure 9. $\mathrm{NH}_{3}$-TPD curves of the SAPO-34 samples synthesized with and without PUa as mesoporogen. 


\subsubsection{Influence of Polyurea as Mesoporogen}

In order to further study the influence of polyurea to the crystallization process, SAPO-34 samples with or without polyurea as mesoporogen were synthesized at different crystallization time, respectively. To eliminate the possible impact of the discrepancy, the starting gel were prepared in one container and divided into several parts. Figure 10a,b show the XRD patterns of the SAPO-34 samples synthesized at different crystallization time. It can be seen that their crystallization processes show a similar trend that begins to crystallize at $12 \mathrm{~h}$ and the crystallinity increases rapidly during the following $12 \mathrm{~h}$. The patterns before $12 \mathrm{~h}$ indicate the phases of $\mathrm{SiO}_{2}$ and $\mathrm{Al}(\mathrm{OH})_{3}$. Figure $10 \mathrm{c}$ represents the relative crystallinity evolution with crystallization time of different samples. The crystallinity was calculated based on the fitting of the area of crystallinity peaks and amorphous peaks by the software Jade 6.0, and the relative crystallinity of fully crystallized SAPO-34 was set as $100 \%$. It can be concluded that the addition of polyurea into the starting gel will decrease the crystallization rate during the crystallization duration of 12 to $36 \mathrm{~h}$. Therefore, the crystallinity keeps unchanged after $36 \mathrm{~h}$, but the yield increase with increasing reaction time.

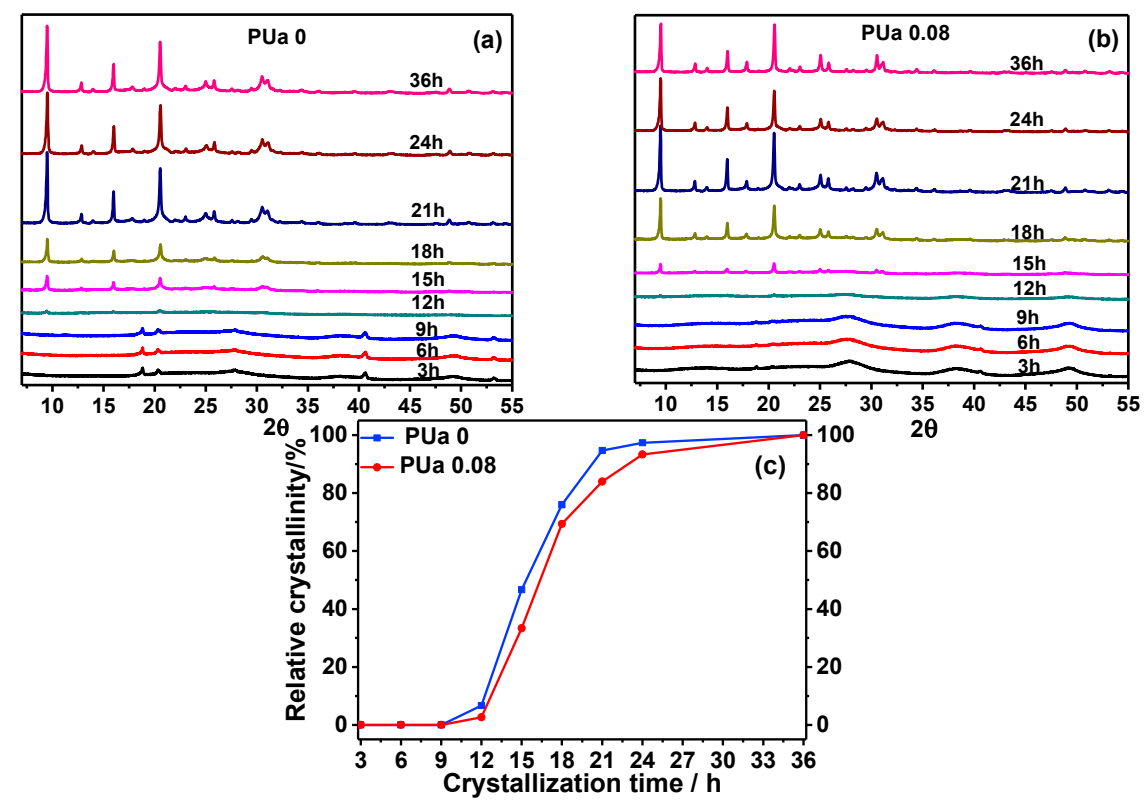

Figure 10. Time-dependent $\mathrm{XRD}$ patterns of $(\mathbf{a}) \mathrm{PUa}_{0},(\mathbf{b}) \mathrm{PUa}_{0.08}$, (c) relative crystallinity evolution with crystallization time.

\subsection{Catalytic Performance for MTO Reaction}

The catalytic performance of the as-synthesized catalyst for methanol conversion to light olefins was evaluated in a fixed bed reactor at $420^{\circ} \mathrm{C}$, and the methanol conversion and products selectivity as a function of time on stream are shown in Figure 11a,b and Figure S4. It can be seen that the hierarchically porous SAPO-34 catalysts synthesized with polyurea as mesoporogen exhibited obviously extended full methanol conversion lifespan compared to conventional microporous SAPO-34 catalyst. The full methanol conversion lifetime increased to 270-320 min compared with $150 \mathrm{~min}$ of conventional SAPO-34 sample synthesized without mesoporogen. It is apparent that the lifetime is prolonged twice. The prolonged lifetime can be attributed to the coke retarding tendency (Table S1) due to the introduction of mesopores/macropores by applying polyurea as mesoporogen. Meanwhile, the total selectivity of ethylene and propylene are also improved for the $\mathrm{PUa}_{0.08}$ and $\mathrm{PUa}_{0.10}$ synthesized with polyurea as mesoprogen. The highest light olefins selectivity of $79 \%$ was afforded at $100 \mathrm{~min}$ using conventional catalyst $\mathrm{PUa}_{0}$, while the highest olefins selectivity for sample $\mathrm{PUa}_{0.08}$ and $\mathrm{PUa}_{0.10}$ increased up to $85 \%$ at the lifetime of $210 \mathrm{~min}$. Nevertheless, the light olefins selectivity begins to decrease when methanol conversion starts to decline due to the deactivation of the catalyst. Compared 
with other modified SAPO-34 catalysts [8,38,47,57-59], the catalytic performance of the as-synthesized mesopores SAPO-34 zeolite for the MTO reaction is also competitive.
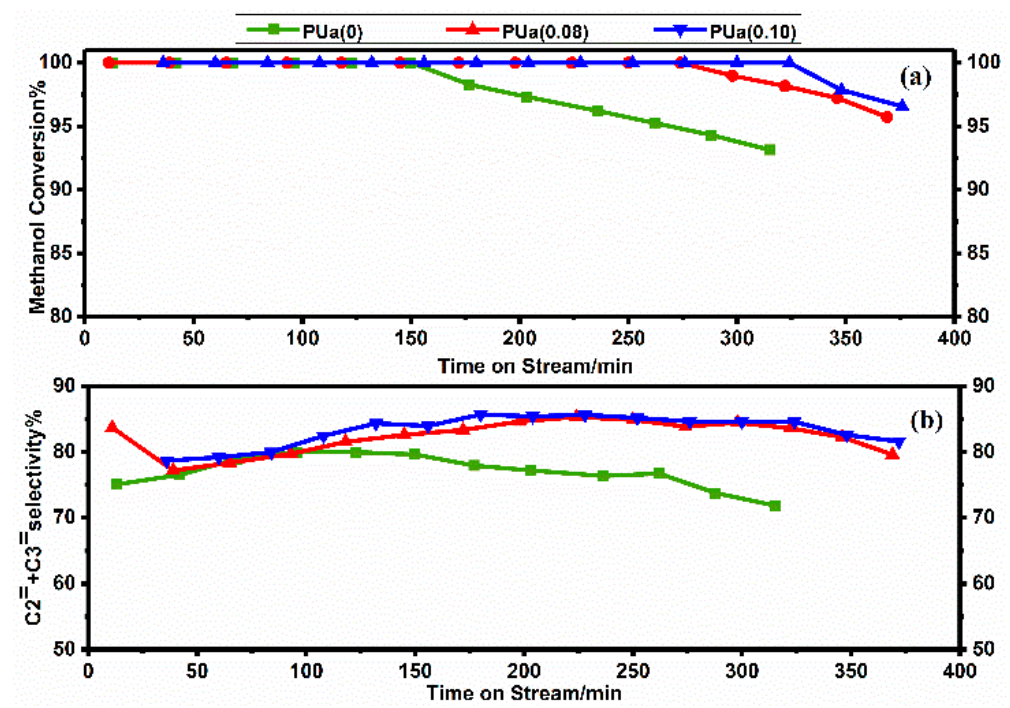

Figure 11. Methanol conversion (a) and product selectivity (b) as a function of time on stream, catalyst: $0.5 \mathrm{~g}$ (mixed with $1 \mathrm{~g} \mathrm{SiC}$ ), temperature $420^{\circ} \mathrm{C}, \mathrm{N}_{2}$ flow rate $=20 \mathrm{~mL} \cdot \mathrm{min}^{-1}, \mathrm{WHSV}=1.5 \mathrm{~h}^{-1}$.

\section{Experimental}

\subsection{Materials}

$\mathrm{CO}_{2}$ (99.999\%, Shanghai Gaisi Industrial Gas, Shanghai, China), 4, 7, 10-trioxa-1, 13-tridecanediamine (TTDDA, 98\%, GC, Aladdin Biochemical Technology Co., Shanghai, China) dried with $4 \AA$ molecular sieves for more than 2 days. Organic template used in the experiment was triethylamine (TEA, 99\%, Guangzhou Chemical Reagent, Guangzhou, China). Other reagents used were aluminum iso-propoxide $\left(\mathrm{Al}\left(\mathrm{OPr}^{\mathrm{i}}\right)_{3}, 98 \%\right.$, Aladdin Biochemical Technology Co., Shanghai, China), phosphoric acid $\left(\mathrm{H}_{3} \mathrm{PO}_{4}, 85\right.$ wt. \%, Aladdin Biochemical Technology Co., Shanghai, China), Tetraethyl orthosilicate (TEOS, $28 \% \mathrm{SiO}_{2}$, Tianjin Damao Chemical Reagent Co., Tianjin, China), $\mathrm{NaOH}$ (Electronic Grade, 99.9\% metals basis, Aladdin Biochemical Technology Co., Shanghai, China).

\subsection{Measurement}

${ }^{1}$ H-NMR spectrum (Bruker BioSpin, Fällanden, Switzerland) was recorded on a Bruker DRX-500 NMR spectrometer with deuterated chloroform $\left(\mathrm{CDCl}_{3}\right)$ as solvent and chemical shifts were referenced to tetramethylsilane (TMS). MALDI-TOF-MS spectra (Bruker BioSpin, Ettlingen, Germany) were recorded on a Bruker ultrafleXtreme MALDI-TOF spectrometer with 2, 5-dihydroxybenzoic acid as the matrix and TFA (trifluoroacetic acid) as solution [60]. The crystalline phase and crystallinity were determined by collecting the powder diffraction pattern on a RIGAKU D-MAX 2200 VPC diffractometer (Rigaku Corporation, Tokyo, Japan) with a Cu-K $\alpha$ radiation $(\lambda=1.5406 \AA)$ operated at $40 \mathrm{kV}$ and $26 \mathrm{~mA}$. Thermo gravimetric (TG) analysis was performed on a PerkinElmer Pyris Diamond TG/DTA instrument (PerkinElmer Inc., Waltham, Massachusetts, USA) with a heating rate of $10 \mathrm{~K} / \mathrm{min}$ to $900{ }^{\circ} \mathrm{C}$ in the air. Nitrogen adsorption-desorption measurements (Micromeritics, Norcross, GA, USA) were carried out on a Micromeritics ASAP 2460 analyzer at $-196{ }^{\circ} \mathrm{C}$, after the sample was degassed at $200^{\circ} \mathrm{C}$ under vacuum. The total surface area was calculated based on the BET equation. The micropore volume, external surface area and micropore surface area were evaluated by using the t-plot method. The mesopore volume was calculated using the BJH method (from desorption). The morphology and crystal size information of the catalysts were obtained by Thermal Field Emission Scanning Electron Microscopy (FE-SEM, Quanta 400F, FEI, Hillsboro, OR, USA). Transmission electron microscopy (TEM) images were recorded with JEOL JEM-2010HR (200 KV, JEOL, Tokyo, Japan) electron microscope. 
The samples were dispersed in ethanol by ultrasonication and then dropped onto the copper grid and dried in oven at $50{ }^{\circ} \mathrm{C}$. Inductively coupled plasma optical emission spectrometry (ICP-OES) analyses were conducted to confirm the chemical compositions of the catalyst with a Perkin-Elmer Optima 8300 instrument (PerkinElmer Inc., Waltham, Massachusetts, USA). The catalyst was dissolved in sodium hydroxide solution, followed by the adjustment of the $\mathrm{PH}$ value with concentrated nitric acid and diluting with $5 \mathrm{wt}$. \% nitric acid until proper concentration. Temperature-programmed desorption of ammonia ( $\mathrm{NH}_{3}$-TPD) was conducted to study the acid properties of the as-synthesized samples and the tests were carried on a Micromeritics Autochem II 2920 device (Micromeritics, Norcross, GA, USA). The samples $(100 \mathrm{mg})$ were pretreated under He flow at $650{ }^{\circ} \mathrm{C}$ for $1 \mathrm{~h}$ to remove the adsorbed gas and water, then cooled down to $100{ }^{\circ} \mathrm{C}$ to saturate the sample with $\mathrm{NH}_{3}$ under a flow of $\mathrm{NH}_{3} / \mathrm{He}$ for $60 \mathrm{~min}$, removed the weakly adsorbed $\mathrm{NH}_{3}$ with a He flow for $30 \mathrm{~min}$, finally measured the desorbed $\mathrm{NH}_{3}$ at a heating rate of $10{ }^{\circ} \mathrm{C} / \mathrm{min}$ from $100{ }^{\circ} \mathrm{C}$ to $650{ }^{\circ} \mathrm{C}$ under He flow $(50 \mathrm{~mL} / \mathrm{min})$. All solid state NMR experiments were performed on a Bruker Avance III 400 spectrometer (Bruker BioSpin, Fällanden, Switzerland) equipped with a $9.4 \mathrm{~T}$ wide-bore magnet. The resonance frequencies in this field strength were 104.2, 161.9 and $79.5 \mathrm{MHz}$ for ${ }^{27} \mathrm{Al}$ MAS NMR, ${ }^{31} \mathrm{P}$ MAS NMR and ${ }^{29} \mathrm{Si}$ MAS NMR, respectively. A $5 \mathrm{~mm}$ MAS probe with a spinning rate of $8 \mathrm{KHz}, 6 \mathrm{KHz}$ and $6 \mathrm{KHz}$ were applied to collect ${ }^{27} \mathrm{Al},{ }^{31} \mathrm{P}$ and ${ }^{29} \mathrm{Si}$ NMR spectra separately. Chemical shifts were referenced to $\left(\mathrm{NH}_{4}\right) \mathrm{Al}$ $\left(\mathrm{SO}_{4}\right)_{2} \cdot 12 \mathrm{H}_{2} \mathrm{O}$ for ${ }^{27} \mathrm{Al}, 85 \% \mathrm{H}_{3} \mathrm{PO}_{4}$ for ${ }^{31} \mathrm{P}$ and 2, 2-dimethyl-2-ilapentane-5-sulfonate sodium salt (DSS) for ${ }^{29} \mathrm{Si}$.

\subsection{Synthesis of $\mathrm{CO}_{2}$-Based Polyurea}

Scheme 1 shows the synthesis process of $\mathrm{CO}_{2}$-based polyurea. Typically, $22 \mathrm{~mL}$ (0.1 mol) of diamine was added into a $50 \mathrm{~mL}$ stainless steel autoclave which placed on a magnetic heating stirrer with a heating jacket, pressurizing the system to $5 \mathrm{MPa}$ with $\mathrm{CO}_{2}$, which is continuously supplied by linking the autoclave to a $\mathrm{CO}_{2}$ cylinder. The reaction was performed at $180{ }^{\circ} \mathrm{C}$ with a stirring speed of $300 \mathrm{rpm}$ for $24 \mathrm{~h}$. The optimal condition were confirmed by a series of reactions (Figure S1). Then cooling the reactor naturally and depressurized the system to atmospheric pressure, the product was purified by dissolving in water and precipitated by being poured into vigorously stirred hexane. The final product was filtered and freeze dried.

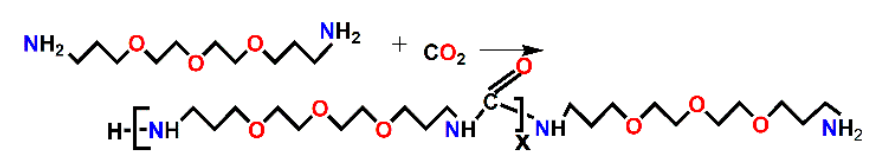

Scheme 1. Synthesis of polyurea.

\subsection{Synthesis of SAPO-34 with Polyurea (PUa) as Structure Directing Reagent}

The starting gel ratios for synthesizing the SAPO-34 catalysts were $\mathrm{Al}_{2} \mathrm{O}_{3}: \mathrm{P}_{2} \mathrm{O}_{5}: \mathrm{SiO}_{2}:$ TEA:PUa: $\mathrm{H}_{2} \mathrm{O}=1: 1: 0.4: 4: \mathrm{x}: 100(\mathrm{x}=0,0.08$ and 0.10$)$. In a typical procedure, the finely ground $\mathrm{Al}\left(\mathrm{OPr}^{\mathrm{i}}\right)_{3}(8.16 \mathrm{~g})$ was mixed with deionized water $(26 \mathrm{~g})$ for about $2 \mathrm{~h}$ at room temperature until a homogeneous solution was obtained, then phosphoric acid ( $4.58 \mathrm{~g})$ was added into the solution dropwise with a continuous stirring for $0.5 \mathrm{~h}$, TEOS (1.66 g) and TEA ( $8.06 \mathrm{~g})$ were sequentially added into the mixture with a vigorously stirring for $0.5 \mathrm{~h}$ respectively. Finally, PUa dissolved in the remaining $10 \mathrm{~mL}$ water was introduced into the mixture to gain a uniform system for another $1 \mathrm{~h}$ stirring. The reaction solution was transferred to a $150 \mathrm{~mL}$ Teflon-lined stainless steel autoclave and heated at $170{ }^{\circ} \mathrm{C}$ for 4 days under static conditions. After the crystallization procedure finished, the autoclave was cooling down immediately with flowing water to guarantee that the crystals wouldn't be re-dissolved during natural cooling. The final solid product was acquired by being centrifuged and washed for 5 times with deionized water, then dried in air at $120^{\circ} \mathrm{C}$ overnight, finally calcined at $600{ }^{\circ} \mathrm{C}$ for $400 \mathrm{~min}$ in muffle furnace with a heating rate of $3{ }^{\circ} \mathrm{C} / \mathrm{min}$. 


\subsection{Evaluation of Catalytic Performance}

The performance of the catalyst for methanol to olefins reaction was carried on a metallic tubular fixed-bed reactor (10 $\mathrm{mm}$ inner diameter) at atmospheric pressure. In a typical procedure, $500 \mathrm{mg}$ of the calcined SAPO-34 (200 mesh) was mixed uniformly with $1 \mathrm{~g} \mathrm{SiC}$ powder, then loaded in the tubular fixed-bed reactor, followed by an one hour pretreatment at $500{ }^{\circ} \mathrm{C}$ under $\mathrm{N}_{2}$ atmosphere. After cooling the reactor to the reaction temperature of $420^{\circ} \mathrm{C}$, the stock was fed by bubbling the liquid methanol $\left(\right.$ at $30^{\circ} \mathrm{C}$ ) through the flowing carrier gas $\left(\mathrm{N}_{2}\right)$ with a rate of $30 \mathrm{~mL} \cdot \mathrm{min}^{-1}$, corresponding to a weight hourly space velocity (WHSV) of $1.5 \mathrm{~h}^{-1}$ (confirmed by the record of the consumed weight of methanol). Online gas chromatograph (GC-7890-II, Shanghai Tianmei Scientific instruments Co., Ltd., Shanghai, China) equipped with Plot-Q column ( $\mathrm{Rt}^{\circledR}{ }^{\circledR} \mathrm{Q}-\mathrm{B}$ - $\mathrm{C} d, 30 \mathrm{~m}, 0.32 \mathrm{~mm}$ ID, Restek Corporation, Bellefonte, PA, USA) and flame ionization detector (FID) was used to determine the species and quantities of the products. The selectivity of the products were calculated based on the amounts of the $\mathrm{CH}_{2}$ species. Methanol conversion and product selectivity were calculated as follows:

$$
\begin{gathered}
\mathrm{CH}_{3} \mathrm{OH} \text { conversion }(\%)=\frac{[\text { Methanol consumed }]}{[\text { Methanol total }]} \times 100 \% \\
\text { Product } i \text { selectivity }(\%)=\frac{[\text { Number of methanol turned into } i \text { product }]}{[\text { Methanol consumed }]} \times 100 \%
\end{gathered}
$$

\section{Conclusions}

In summary, the micro-mesopores SAPO-34 molecular sieve catalyst can be readily synthesized by introducing a novel $\mathrm{CO}_{2}$-based polyurea with affluent amine groups, ether segments and carbonyl groups into the starting gel as mesoporogen under hydrothermal conditions. The as-synthesized SAPO-34 crystals show a center-hollowed cubic-like morphology with heterogeneous size distribution mesopores. Due to the formation of defects and voids and descended acidity in the crystals, the catalysts exhibit superior catalytic performance for MTO reaction with more than twice prolonged catalytic lifespan and improvement of selectivity for light olefins compared with conventional microporous SAPO-34. The methodology developed in this work provides a potential alternative way to synthesize micro-mesopores SAPO-34 molecular sieves that can greatly enhance the catalytic performance for methanol to olefins (MTO) reaction, especially lifetime and olefins selectivity.

Supplementary Materials: The following are available online at http:/ / www.mdpi.com/2073-4344/9/1/16/s1, Figure S1. Molecular weight (Mn) of PUa with the change of Pressure (a) and Temperature (b), Figure S2. XRD patterns of SAPO-34 sample synthesized with a $\mathrm{PUa} / \mathrm{Al}_{2} \mathrm{O}_{3}$ ratio of 0.20 , Figure S3. SEM images of SAPO-34 sample synthesized with a PUa/Al2O3 ratio of 0.20, Figure S4. Product (except for ethylene and propylene) selectivity of methanol conversion reaction for different SAPO-34 catalyst, (a) $\mathrm{PUa}_{0}$, (b) $\mathrm{PUa}_{0.08}$, (c) $\mathrm{PUa}_{0.10}$, Table S1. The variation of coke formation in methanol conversion over different SAPO-34 catalysts.

Author Contributions: Y.Y., J.Q., M.X. and Y.M., conceived and designed the experiments; Y.Y. and J.Q. performed the experiments and analyzed the data; D.H. and S.W. contributed analysis tools. Y.Y. wrote this paper.

Funding: This research was funded by National Natural Science Foundation of China (Grant No. 21376276), Guangdong Province Sci. \& Tech. Bureau (Grant No. 2017B090901003, 2016B010114004, 2016A050503001), and Fundamental Research Funds for the Central Universities.

Acknowledgments: The authors would like to thank the National Natural Science Foundation of China (Grant No. 21376276), Guangdong Province Sci. \& Tech. Bureau (Grant No. 2017B090901003, 2016B010114004, 2016A050503001), and Fundamental Research Funds for the Central Universities for financial support of this work.

Conflicts of Interest: The authors declare no conflict of interest. 


\section{References}

1. Tian, P.; Wei, Y.X.; Ye, M.; Liu, Z.M. Methanol to Olefins (MTO): From Fundamentals to Commercialization. ACS Catal. 2015, 5, 1922-1938. [CrossRef]

2. Dai, W.L.; Wang, C.M.; Dyballa, M.; Wu, G.J.; Guan, N.J.; Li, L.D.; Xie, Z.K.; Hunger, M. Understanding the Early Stages of the Methanol-to-Olefin Conversion on H-SAPO-34. ACS Catal. 2015, 5, 317-326. [CrossRef]

3. Sun, Q.; Wang, N.; Xi, D.; Yang, M.; Yu, J. Organosilane surfactant-directed synthesis of hierarchical porous SAPO-34 catalysts with excellent MTO performance. Chem. Commun. 2014, 50, 6502-6505. [CrossRef] [PubMed]

4. Chen, D.; Moljord, K.; Holmen, A. A methanol to olefins review: Diffusion, coke formation and deactivation SAPO type catalysts. Microporous Mesoporous Mater. 2012, 164, 239-250. [CrossRef]

5. Olsbye, U.; Svelle, S.; Bjørgen, M.; Beato, P.; Janssens, T.V.W.; Joensen, F.; Bordiga, S.; Lillerud, K.P. Conversion of Methanol to Hydrocarbons: How Zeolite Cavity and Pore Size Controls Product Selectivity. Angew. Chem. Int. Ed. 2012, 51, 5810-5831. [CrossRef] [PubMed]

6. Yang, H.; Liu, Z.; Gao, H.; Xie, Z. Synthesis and catalytic performances of hierarchical SAPO-34 monolith. J. Mater. Chem. 2010, 20, 3227-3231. [CrossRef]

7. Gao, B.B.; Yang, M.; Qiao, Y.Y.; Li, J.Z.; Xiang, X.; Wu, P.F.; Wei, Y.X.; Xu, S.T.; Tian, P.; Liu, Z.M. A low-temperature approach to synthesize low-silica SAPO-34 nanocrystals and their application in the methanol-to-olefins (MTO) reaction. Catal. Sci. Technol. 2016, 6, 7569-7578. [CrossRef]

8. Sun, Q.M.; Wang, N.; Guo, G.Q.; Chen, X.X.; Yu, J.H. Synthesis of tri-level hierarchical SAPO-34 zeolite with intracrystalline micro-meso-macroporosity showing superior MTO performance. J. Mater. Chem. A 2015, 3, 19783-19789. [CrossRef]

9. Wang, C.; Yi, X.F.; Xu, J.; Qi, G.D.; Gao, P.; Wang, W.Y.; Chu, Y.Y.; Wang, Q.; Feng, N.D.; Liu, X.L.; et al. Experimental Evidence on the Formation of Ethene through Carbocations in Methanol Conversion over H-ZSM-5 Zeolite. Chem. Eur. J. 2015, 21, 12061-12068. [CrossRef] [PubMed]

10. Yaripour, F.; Shariatinia, Z.; Sahebdelfar, S.; Irandoukht, A. Effect of boron incorporation on the structure, products selectivities and lifetime of H-ZSM-5 nanocatalyst designed for application in methanol-to-olefins (MTO) reaction. Microporous Mesoporous Mater. 2015, 203, 41-53. [CrossRef]

11. Sun, X.Y.; Mueller, S.; Shi, H.; Haller, G.L.; Sanchez-Sanchez, M.; van Veen, A.C.; Lercher, J.A. On the impact of co-feeding aromatics and olefins for the methanol-to-olefins reaction on HZSM-5. J. Catal. 2014, 314, 21-31. [CrossRef]

12. Zhu, X.C.; Hofmann, J.P.; Mezari, B.; Kosinov, N.; Wu, L.L.; Qian, Q.Y.; Weckhuysen, B.M.; Asahina, S.; Ruiz-Martínez, J.; Hensen, E.J.M. Trimodal Porous Hierarchical SSZ-13 Zeolite with Improved Catalytic Performance in the Methanol-to-Olefins Reaction. ACS Catal. 2016, 6, 2163-2177. [CrossRef]

13. Zhu, X.C.; Kosinov, N.; Kubarev, A.V.; Bolshakov, A.; Mezari, B.; Valastyan, I.; Hofmann, J.P.; Roeffaers, M.B.J.; Sarkadi-Pribóczki, E.; Hensen, E.J.M. Probing the Influence of SSZ-13 Zeolite Pore Hierarchy in Methanol-to-Olefins Catalysis by Using Nanometer Accuracy by Stochastic Chemical Reactions Fluorescence Microscopy and Positron Emission Profiling. ChemCatChem 2017, 9, 3470-3477. [CrossRef]

14. Deimund, M.A.; Harrison, L.; Lunn, J.D.; Liu, Y.; Malek, A.; Shayib, R.; Davis, M.E. Effect of Heteroatom Concentration in SSZ-13 on the Methanol-to-Olefins Reaction. ACS Catal. 2016, 6, 542-550. [CrossRef]

15. Lok, B.M.; Messina, C.A.; Patton, R.L.; Gajek, R.T.; Cannan, T.R.; Flanigen, E.M. Silicoalumino-phosphate molecular sieves: Another new class of microporous crystalline inorganic solids. J. Am. Chem. Soc. 1984, 106, 6092-6093. [CrossRef]

16. Kang, M.; Inui, T. Effects of decrease in number of acid sites located on the external surface of Ni-SAPO-34 crystalline catalyst by the mechanochemical method. Catal. Lett. 1998, 53, 171-176. [CrossRef]

17. Sastre, G.; Lewis, D.W.; Catlow, C.R.A. Modeling of Silicon Substitution in SAPO-5 and SAPO-34 Molecular Sieves. Acc. Chem. Res. 1997, 101, 5249-5262. [CrossRef]

18. Izadbakhsh, A.; Farhadi, F.; Khorasheh, F.; Sahebdelfar, S.; Asadi, M.; Feng, Y.Z. Effect of SAPO-34's composition on its physico-chemical properties and deactivation in MTO process. Appl. Catal. A 2009, 364, 48-56. [CrossRef]

19. Liang, J.; Li, H.; Zhao, S.; Guo, W.; Wang, R.; Ying, M. Characteristics and performance of SAPO-34 catalyst for methanol-to-olefin conversion. Appl. Catal. 1990, 64, 31-40. [CrossRef] 
20. Stöcker, M. Methanol-to-hydrocarbons: Catalytic materials and their behavior. Microporous Mesoporous Mater. 1999, 29, 3-48. [CrossRef]

21. Dahl, I.M.; Mostad, H.; Akporiaye, D.; Wendelbo, R. Structural and chemical influences on the MTO reaction: A comparison of chabazite and SAPO-34 as MTO catalysts. Microporous Mesoporous Mater. 1999, 29, 185-190. [CrossRef]

22. Haw, J.F.; Song, W.; Marcus, D.M.; Nicholas, J.B. The mechanism of methanol to hydrocarbon catalysis. Acc. Chem. Res. 2003, 36, 317-326. [CrossRef] [PubMed]

23. Arstad, B.; Kolboe, S. The reactivity of molecules trapped within the SAPO-34 cavities in the methanol-to-hydrocarbons reaction. J. Am. Chem. Soc. 2001, 123, 8137-8138. [CrossRef] [PubMed]

24. Chen, D.; Grønvold, A.; Moljord, K.; Holmen, A. Methanol conversion to light olefins over SAPO-34: Reaction network and deactivation kinetics. Ind. Eng. Chem. Res. 2007, 46, 4116-4123. [CrossRef]

25. Karger, J. Random walk through two-channel networks: A simple means to correlate the coefficients of anisotropic diffusion in ZSM-5 type zeolites. J. Phys. Chem. 1991, 14, 5558-5560. [CrossRef]

26. Camara, L.; Rajagopal, K.; Aranda, D. The effects of pore structure on catalyst deactivation by coke formation. Stud. Surf. Sci. Catal. 2001, 139, 61-68.

27. Beyne, A.O.E.; Froment, G.F. A percolation approach for the modeling of deactivation of zeolite catalysts by coke formation: Diffusional limitations and finite rate of coke growth. Chem. Eng. Sci. 1993, 3, 503-511. [CrossRef]

28. Sahimi, M.; Gavalas, G.R.; Tsotsis, T.T. Statistical and continuum models of fluid-solid reactions in porous media. Chem. Eng. Sci. 1990, 6, 1443-1502. [CrossRef]

29. Chen, D.; Rebo, H.P.; Holmen, A. Diffusion and deactivation during methanol conversion over SAPO-34: A percolation approach. Chem. Eng. Sci. 1999, 54, 3465-3473. [CrossRef]

30. Guo, X.; Liu, Z.; Zhong, B. Monte Carlo simulation of coke formation in zeolites. Microporous Mesoporous Mater. 1998, 23, 203-209. [CrossRef]

31. Sahimi, M. Nonlinear transport processes in disordered media. AIChE J. 1993, 3, 369-386. [CrossRef]

32. Mayagoitia, V.; Rojas, F.; Kornhauser, I.; Pérez-Aguilar, H. Modeling of porous media and surface structures: Their true essence as networks. Langmuir 1997, 5, 1327-1331. [CrossRef]

33. Cai, D.; Wang, Q.; Jia, Z.; Ma, Y.; Cui, Y.; Muhammad, U.; Wang, Y.; Qian, W.; Wei, F. Equilibrium analysis of methylbenzene intermediates for a methanol-to-olefins process. Catal. Sci. Technol. 2016, 5, 1297-1301. [CrossRef]

34. Janssens, T.V.W. A new approach to the modeling of deactivation in the conversion of methanol on zeolite catalysts. J. Catal. 2009, 2, 130-137. [CrossRef]

35. Cai, D.L.; Ma, Y.H.; Hou, Y.L.; Cui, Y.; Jia, Z.; Zhang, C.X.; Wang, Y.; Wei, F. Establishing a discrete Ising model for zeolite deactivation: Inspiration from the game of Go. Catal. Sci. Technol. 2017, 7, 2440-2444. [CrossRef]

36. Perez-Ramirez, J.; Christensen, C.H.; Egeblad, K.; Christensen, C.H.; Groen, J.C. Hierarchical zeolites: Enhanced utilisation of microporous crystals in catalysis by advances in materials design. Chem. Soc. Rev. 2008, 37, 2530-2542. [CrossRef]

37. Li, K.; Valla, J.; Garcia-Martinez, J. Realizing the Commercial Potential of Hierarchical Zeolites: New Opportunities in Catalytic Cracking. ChemCatChem 2014, 6, 46-66. [CrossRef]

38. Chen, X.X.; Xi, D.Y.; Sun, Q.M.; Wang, N.; Dai, Z.Y.; Fan, D.; Valtchev, V.; Yu, J.H. A top-down approach to hierarchical SAPO-34 zeolites with improved selectivity of olefin. Microporous Mesoporous Mater. 2016, 234, 401-408. [CrossRef]

39. Sun, C.; Wang, Y.Q.; Wang, Z.; Chen, H.B.; Wang, X.; Li, H.Y.; Sun, L.Y.; Fan, C.Y.; Zhang, X. Fabrication of hierarchical ZnSAPO-34 by alkali treatment with improved catalytic performance in the methanol-to-olefin reaction. Comptes Rendus Chim. 2018, 21, 61-70. [CrossRef]

40. Schmidt, I.; Madsen, C.; Jacobsen, C.J.H. Confined space synthesis: A novel route to nanosized zeolites. Inorg. Chem. 2000, 39, 2279-2283. [CrossRef]

41. Jacobsen, C.J.H.; Madsen, C.; Janssens, T.V.W.; Jakobsen, H.J.; Skibsted, J. Zeolites by confined space synthesis-Characterization of the acid sites in nanosized ZSM-5 by ammonia desorption and Al-27/Si-29-MAS NMR spectroscopy. Microporous Mesoporous Mater. 2000, 39, 393-401. [CrossRef]

42. Schmidt, F.; Paasch, S.; Brunner, E.; Kaskel, S. Carbon templated SAPO-34 with improved adsorption kinetics and catalytic performance in the MTO-reaction. Microporous Mesoporous Mater. 2012, 164, 214-221. [CrossRef] 
43. Wang, C.; Yang, M.; Tian, P.; Xu, S.; Yang, Y.; Wang, D.; Yuan, Y.; Liu, Z. Dual template-directed synthesis of SAPO-34 nanosheet assemblies with improved stability in the methanol to olefins reaction. J. Mater. Chem. A 2015, 3, 5608-5616. [CrossRef]

44. Egeblad, K.; Christensen, C.H.; Kustova, M.; Christensen, C.H. Templating mesoporous zeolites. Chem. Mater. 2008, 20, 946-960. [CrossRef]

45. Xiao, F.S.; Wang, L.F.; Yin, C.Y.; Lin, K.F.; Yan, D.; Li, J.X.; Xu, R.R.; Su, D.S.; Schlögl, R.; Yokoi, T.; et al. Catalytic properties of hierarchical mesoporous zeolites templated with a mixture of small organic ammonium salts and mesoscale cationic polymers. Angew. Chem. Int. Ed. 2006, 118, 3162-3165. [CrossRef]

46. Tanakaa, S.; Fukui, R.; Miyake, Y. Synthesis of ordered mesoporous silicoaluminophosphates by using LTA zeolite precursors dissolved under acidic conditions. Mater. Lett. 2013, 92, 259-262. [CrossRef]

47. Wang, F.; Sun, L.; Chen, C.L.; Chen, Z.; Zhang, Z.W.; Wei, G.H.; Jiang, X.M. Polyethyleneimine templated synthesis of hierarchical SAPO-34 zeolites with uniform mesopores. RSC Adv. 2014, 4, 46093-46096. [CrossRef]

48. Meng, X.; Xiao, F.S. Mesoporous Zeolites: Preparation, Characterization, Applications; Garcia-Martinez, J., Li, K.H., Eds.; Wiley-VCH: Weinheim, Germany, 2015; pp. 199-226.

49. Song, Q.W.; Zhou, Z.H.; He, L.N. Efficient, selective and sustainable catalysis of carbon dioxide. Green Chem. 2017, 19, 3707-3728. [CrossRef]

50. Wang, Y.; Chen, S.L.; Jiang, Y.J.; Cao, Y.Q.; Chen, F.; Chang, W.K.; Gao, Y.L. Influence of template content on selective synthesis of SAPO-18, SAPO-18/34 intergrowth and SAPO-34 molecular sieves used for methanol-to-olefins process. RSC Adv. 2016, 6, 104985-104994. [CrossRef]

51. Álvaro-Muñoz, T.; Márquez-Álvarez, C.; Sastre, E. Use of different templates on SAPO-34 synthesis. Effect on the acidity and catalytic activity in the MTO reaction. Catal. Today 2012, 179, 27-34. [CrossRef]

52. Álvaro-Muñoz, T.; Márquez-Álvarez, C.; Sastre, E. Aluminium chloride: A new aluminum source to prepare SAPO-34 catalysts with enhanced stability in the MTO process. Appl. Catal. A 2014, 472, 72-79. [CrossRef]

53. Van den Bergh, J.; Gascon, J.; Kapteijn, F. Zeolites, Catalysis; Wiley-VCH GmbH \& Co. KGaA: Weinheim, Germany, 2010; pp. 361-387.

54. Watanabe, Y.; Koiwai, A.; Takeuchi, H.; Hyodo, S.; Noda, S. Multinuclear NMR studies on the thermal stability of SAPO-34. J. Catal. 1993, 143, 430-436. [CrossRef]

55. Hasha, D.; de Saldarriaga, L.S.; Saldarriaga, C.; Hathaway, P.E.; Cox, D.F.; Davis, M.E. Studies of Silicoaluminophosphates with the Sodalite Structure. J. Am. Chem. Soc. 1988, 110, 2127-2135. [CrossRef]

56. Wang, J.; Fan, D.Q.; Yu, T.; Wang, J.Q.; Hao, T.; Hu, X.Q.; Shen, M.Q.; Li, W. Improvement of low-temperature hydrothermal stability of $\mathrm{Cu} / \mathrm{SAPO}-34$ catalysts by $\mathrm{Cu}^{2+}$ species. J. Catal. 2015, 322, 84-90. [CrossRef]

57. Wang, Y.; Chen, S.L.; Gao, Y.L.; Cao, Y.Q.; Zhang, Q.; Chang, W.K.; Benziger, J.B. Enhanced methanol to Olefins Catalysis by Physical Mixtures of SAPO-34 Molecular and MgO. ACS Catal. 2017, 7, 5572-5585. [CrossRef]

58. Zhang, Y.C.; Deng, Z.Y.; Zhu, K.K.; Zhou, X.G. Insights into the growth of small-sized SAPO-34 crystals synthesized by a vapor-phase transport method. CrystEngComm 2015, 17, 3214-3218. [CrossRef]

59. Zheng, J.W.; Ding, J.J.; Jin, D.L.; Ye, G.H.; Zhu, K.K.; Zhou, X.G.; Yang, W.M.; Yuan, W.K. The tailored synthesis of nanosize SAPO-34 via time-controlled silicon release enabled by an organosilane precursor. Chem. Coummun. 2017, 53, 6132-6135. [CrossRef]

60. Ying, Z.; Wu, C.Y.; Jiang, S.; Shi, R.H.; Zhang, B.; Zhang, C.; Zhao, F.Y. Synthesis of polyurethane-urea from double $\mathrm{CO}_{2}$-route oligomers. Green Chem. 2016, 18, 3614-3619. [CrossRef]

(C) 2018 by the authors. Licensee MDPI, Basel, Switzerland. This article is an open access article distributed under the terms and conditions of the Creative Commons Attribution (CC BY) license (http://creativecommons.org/licenses/by/4.0/). 